\title{
Blockade of recombinant human IL-6 by tocilizumab suppresses matrix metalloproteinase -9 production in the C28/I2 immortalized human chondrocyte cell line
}

\author{
Evan C. Meszaros ${ }^{1}$, Wissam Dahoud ${ }^{2}$, Sam Mesiano ${ }^{2}$ and Charles J. Malemud ${ }^{1 *}$ \\ ${ }^{1}$ Division of Rheumatic Diseases, Department of Medicine, Arthritis Research Laboratory, Case Western Reserve University School of Medicine and University \\ Hospitals Case Medical Center, Cleveland, Ohio 44106, USA \\ ${ }^{2}$ Department of Reproductive Biology, Case Western Reserve University School of Medicine, Cleveland, OH, USA
}

\begin{abstract}
Two immortalized human juvenile chondrocyte cell lines, T/C28a2 and C28/I2, were employed to determine the extent to which recombinant human (rh) IL-6 or rh-TNF- $\alpha$ increased the production of matrix metalloproteinase-9 (MMP-9). The effect of rhIL-6 on neutrophil gelatinase-associated lipocalin (NGAL) was also assessed. Although C28/I2 chondrocytes incubated with rhIL-6 (50 ng/ml) increased MMP-9 production which could not be mimicked by the T/C28a2 chondrocyte line, the effect of rhTNF- $\alpha$ on MMP- 9 was more robust than with rhIL-6. The combinations of rhIL-6 and soluble IL-6 receptor- $\alpha$ (sIL-6R $\alpha$ ) or rhIL-6 and tocilizumab (TCZ), a fully-humanized recombinant monoclonal antibody that neutralizes the interaction between IL-6 and IL-6R significantly reduced MMP-9 production by C28/I2 chondrocytes. However, TCZ had no effect on rhTNF- $\alpha$-induced MMP-9 production. By contrast, rhIL- 6 did not increase the production of NGAL by C28/I2 chondrocytes although the number of NGAL-positive cells was significantly reduced by sIL-6R compared to its control group, but not by the combination of rhIL-6 plus TCZ compared to rhIL-6. In summary, these results showed that rhIL-6 stimulated the production of MMP-9, but not NGAL, in the C28/I2 chondrocyte line. TCZ or sIL-6R $\alpha$ suppressed rhIL-6-induced MMP-9 production.
\end{abstract}

\section{Introduction}

Matrix metalloproteinase-9 (MMP-9; gelatinase B; $92 \mathrm{kDa}$ gelatinase; $92 \mathrm{kDa}$ type IV collagenase) is a critical MMP in mediating the progression of various arthritic conditions [1]. MMP-9 has the capacity to degrade several articular cartilage extracellular matrix (ECM) proteins, including aggrecan, link protein, and type II collagen, all of which help maintain normal cartilage biomechanical functions [1]. Importantly, in various types of arthritis, chondrocyte MMP-9 gene expression is significantly up-regulated in response to the elevated levels of pro-inflammatory cytokines in the synovial fluid milieu, exemplified by intereukin-6 (IL-6), IL-1 $\beta$, IL-17, and tumor necrosis factor- $\alpha$ (TNF- $\alpha)$ [1-3].

To probe the contribution of each of those cytokines to MMP-9 gene expression by articular chondrocytes in vitro would generally require that specific inhibitors for each of them be individually tested. In that regard, the effect of IL- $1 \beta$ or TNF- $\alpha$ blockade on MMP synthesis was previously reported with the results showing that IL-1 receptor antagonist or TNF- $\alpha$ blocking monoclonal antibodies inhibited MMP production [4]. However, the contribution of IL-6 to MMP-9 production by cultured human chondrocytes remains to be fully elucidated. Therefore, to achieve this objective, the extent to which tocilizumab (TCZ), a recombinant fully humanized $\operatorname{IgG1}(\kappa)$ monoclonal antibody that neutralizes the interaction between IL- 6 and the IL-6 receptor- $\alpha$ (IL-6R $\alpha$ ) [5] inhibits recombinant human (rh)-IL6-mediated MMP-9 production was determined in the immortalized human juvenile T/C28a2 and C28/I2 chondrocyte lines. These human chondrocyte lines were employed for this analysis because they had been previously shown to express cartilage-specific extracellular matrix protein genes [6,7]. T/C28a2 and C28/I2 chondrocytes also expressed several other molecules characteristic of authentic human chondrocytes, most notably the molecular signature SOX9 gene, considered the "master" transcriptional regulator of several cartilagespecific genes as the type II collagen (COL2A1) gene and the aggrecan (AGRN) gene [6-8].

The effect of rhIL-6 on the synthesis of chondrocyte-derived neutrophil gelatinase-associated lipocalin (NGAL) was also evaluated. The rationale for analyzing NGAL production by C28/I2 chondrocytes stemmed from our previously reported finding that chondrocytes obtained from human osteoarthritis knee cartilage synthesized NGAL in response to IL-1 $\beta$ [9]. In addition, we showed that NGAL in synovial fluids obtained from patients with end-stage osteoarthritis was found in a complex with MMP-9. Moreover, we proved that the MMP-9/ NGAL complex preserved MMP-9 activity by demonstrating that this complex prevented MMP-9 from being degraded, thus preserving MMP-9 activity [10].

Correspondence to: Charles J. Malemud, Division of Rheumatic Diseases, Department of Medicine, University Hospitals Case Medical Center, Foley Medical Building, 2061 Cornell Road, Rm. 207, Cleveland, OH 44106-5076, Tel: (216) 844-7846; Mobile: (216) 536-1945 (Preferred); Fax: (216) 844-2288, E-mail: cjm4@cwru.edu

Keywords: IL-6, tocilizumab, matrix, metalloproteinase-9, c28/i2 immortalized human chondrocyte

Received: Ju1y 08, 2015; Accepted: August 04, 2015; Published: August 08, 2015 


\section{Materials and methods}

\section{Human chondrocyte cell lines}

The immortalized human juvenile chondrocyte cell lines, T/C28a2 and C28/I2, were obtained from the laboratory of Professor Mary B. Goldring [Hospital for Special Surgery/Weill Medical College of Cornell University (New York, New York.)].

\section{PANC-1}

PANC-1, a line of pancreatic carcinoma cells, was obtained from the American Type Culture Collection (Manassas, VA).

\section{MMP-9 ELISA/NGAL ELISA, anti-MMP-9/anti-NGAL Immunocytochemistry (ICC)}

An ELISA kit containing anti-MMP-9 antibody was purchased from Aviva Systems (San Diego, CA). An ELISA kit for the detection of NGAL was purchased from Pierce Biotechnology (Rockford, IL). The anti-MMP-9 antibody and anti-NGAL antibody employed for ICC were purchased from Abcam (Cambridge, MA). The human anti-MMP-9 antibody used for ICC was a rabbit polyclonal antibody produced against a rat recombinant fragment of the MMP-9 catalytic domain. According to the manufacturer, this anti-MMP-9 antibody is reactive with both pro-MMP-9 and activated MMP-9. For the NGAL ICC, the immunogen used to produce the anti-NGAL antibody was a synthetic peptide corresponding to the 38-53 amino acid sequence, LQPGFWTERFQGRWFV located at the N-terminus of rat NGAL.

\section{Recombinant human (rh) IL-6, rhTNF- $\alpha$ and soluble IL-6 Receptor- $\alpha$ (sIL-6R $\alpha)$}

The cytokines, rhIL-6, and rhTNF- $\alpha$, and soluble IL-6Ra (sIL-6R) were purchased from various commercial vendors.

\section{Tocilizumab (TCZ)}

Tocilizumab (TCZ) was obtained through a research contract between Genentech/Roche Group (South San Francisco, CA) and Case Western Reserve University.

\section{Human T/C28a2, C28/I2 Chondrocytes and PANC-1}

T/C28a2 or C28/I2 chondrocytes were maintained in Dulbecco's Modified Eagle's Medium (DMEM)/F12 medium (1:1 ratio) supplemented with $10 \%(\mathrm{v} / \mathrm{v})$ fetal bovine serum (FBS). PANC-1 was maintained in continuous culture according to instructions provided by the American Tissue Culture Collection.

\section{Experimental Conditions for MMP-9/NGAL ELISA and MMP-9/NGAL ICC}

TC28a 2 or C28/I 2 chondrocytes $\left(3 \times 10^{5}\right.$ cells $/ \mathrm{ml}$, ELISA; $10^{5}$ cells/ $\mathrm{ml}$, ICC) were incubated in DMEM/F12 (1:1) containing 0.5\% FBS under the following conditions: "No additions" (control), rhIL-6 (50 $\mathrm{ng} / \mathrm{ml})$, sIL-6R (30 ng/ml); rhTNF- $\alpha$ (20 ng/ml), TCZ (200-800 ng/ml), rhIL-6 plus TCZ, rhTNF- $\alpha$ plus TCZ, or rhIL-6 plus sIL-6R each for $60 \mathrm{~min}$ and $4 \mathrm{hrs}$. The concentrations of rhIL- 6 and sIL-6R used in this study were based on previously published data, which showed 1) that IL-6 $(50 \mathrm{ng} / \mathrm{ml})$ activated chondrocyte JAK/STAT and ERK-MAPK signaling [11]; and 2) that the concentration of sIL-6R $(30 \mathrm{ng} / \mathrm{ml})$ approximated the maximal concentration of sIL-6R reportedly found in RA synovial fluid (range 10-40 ng/ml) [12].

PANC-1 was employed as the positive control for MMP-
9 production because PANC-1 had previously been shown to over-produce MMP-9 [13]. In addition, MMP-9 was found to be substantially increased over control levels in response to phorbol myristate acetate (PMA) [13]. Thus, PANC-1, T/C28a2 and C28/I2 chondrocytes were employed for the MMP-9 ELISA and PANC-1 and C28/I2 chondrocytes for the anti-MMP-9 antibody ICC. For the MMP9 ELISA, the concentration of MMP- 9 in T/C28a2, C28/I2 or PANC-1 was determined from serial dilutions of the protein lysate. The average of duplicate ELISA determinations was used to calculate the amount of MMP-9 (pg/ml) produced by the cells.

For ICC, the number of anti-MMP-9-negative or anti-MMP-9positive PANC-1 or C28/I2 chondrocytes and NGAL-negative or NGAL-positive chondrocytes were enumerated by quantifying the mean intensity of 6 sampled areas in photomicrographs from each of the control and treatment groups using the Metamorph software program. The mean intensities were then normalized to the negative control to determine the number of MMP-9 or NGAL-positive cells reported in arbitrary units.

\section{Data analysis}

ELISA Analysis: The amount of MMP-9 or NGAL (pg/ml) produced by $\mathrm{C} 28 / \mathrm{I} 2$ chondrocytes was calculated using the average of duplicate determinations from their respective ELISA. Chi-square (www.socscistatistics.com/tests/chisquare/default2.aspx) was used to calculate the significance of differences between the amount of MMP-9 produced by C28/I2 chondrocytes treated with rhIL- 6 alone (50 ng/ $\mathrm{ml}$ ) and rhIL-6 plus TCZ, at various concentrations with an expected difference of $\Delta=+/-20 \%$ between the groups employed in the chisquare $2 \times 2$ table.

ICC Analysis: The frequency of MMP-9-positive or NGAL-positive cells in the control groups $(n=5)$ or the various treatment groups $(n=5)$ was calculated from the computer-generated anti-MMP-9 antibody/ anti-NGAL antibody ICC results. The results shown as "arbitrary units" was then analyzed by determining whether the comparison groups had equal variances. Then the F-value was calculated using the one-way ANOVA calculator (turner.faculty.swau.edu/mathematics/ math241/materials/anova). To calculate a p-value, the Student's t-test was employed for comparison of groups with equal variances where $\mathrm{p}<0.05$ was considered significant.

\section{Results}

MMP-9 production is increased by rhIL-6 and rhTNF- $\alpha$ : Effect of sIL-6R and TCZ

A standard curve was produced for the MMP-9 ELISA which showed that the concentration of MMP-9 as a function of OD $_{450 \mathrm{~nm}}$ was linear (Figure 1). This standard curve was used to calculate the amount of MMP-9 $(\mathrm{pg} / \mathrm{ml})$ produced by T/C28a 2 or C28/I2 chondrocytes or by PANC-1 cells using direct interpolation of the $\mathrm{OD}_{450 \mathrm{~nm}}$ measurements performed on the various cell lysates.

Incubation of $\mathrm{C} 28 / \mathrm{I} 2$ chondrocytes, but not $\mathrm{T} / \mathrm{C} 28 \mathrm{a} 2$ chondrocytes, with rhIL-6 increased MMP-9 production. MMP-9 production was reduced when rhIL-6 was combined with either sIL-6R or TCZ (Figure 2). Although rhIL-6 also increased MMP-9 in PANC-1 cells, the combination of rhIL-6 plus TCZ did not inhibit MMP-9. Of note, the effect of rhTNF- $\alpha$ on MMP-9 production by T/C28a2 or C28/ I2 chondrocytes was far more robust than with rhIL-6 (Figure 2). However, the combination of rhTNF- $\alpha$ and TCZ had no effect on MMP9 production by $\mathrm{T} / \mathrm{C} 28 \mathrm{a} 2$ chondrocytes whereas the combination of 


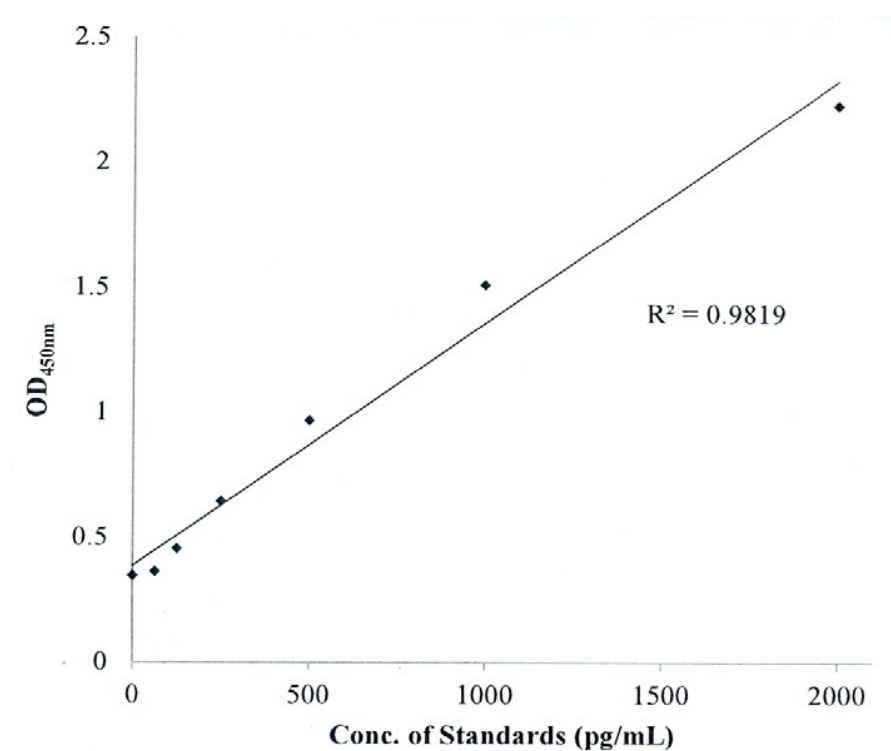

Figure 1. MMP-9 ELISA Standard Curve.

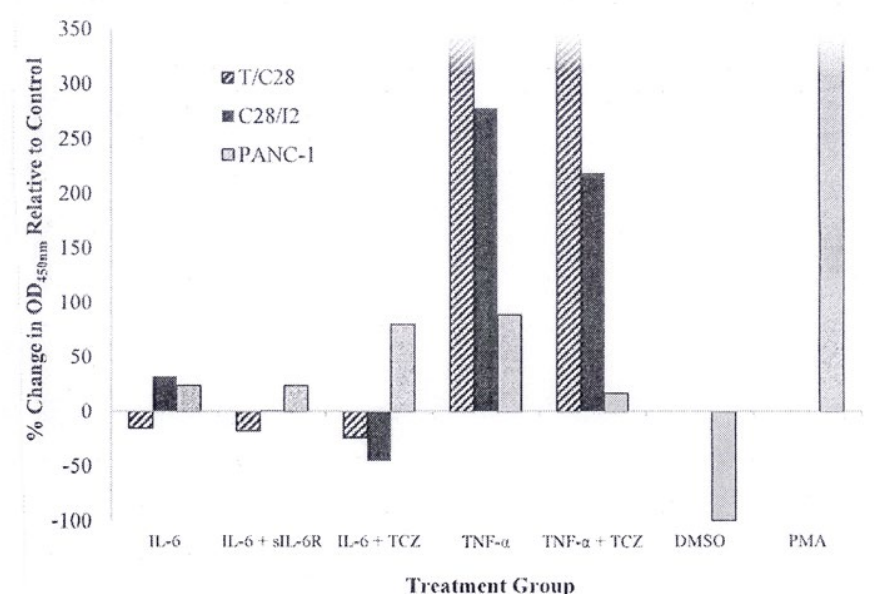

Figure 2. MMP-9 Production by T/C28a2, C28/I2 Chondrocytes and PANC-1 Cells Measured by an MMP-9 ELISA. MMP-9 Production: \% Change OD ${ }_{450}$ Relative to the "No Additions" Control Group. The concentration of cytokines, inhibitors or other factors for each group were rhIL-6-50 ng/ml; sIL-6R-30 ng/ml; TCZ-200 ng/ml; rhTNF- $\alpha-20$ $\mathrm{ng} / \mathrm{ml}$; PMA-30.7 ng/ml. Values shown for MMP-9 produced by T/C28a2 chondrocytes incubated with either rhTNF- $\alpha$ or rhTNF- $\alpha$ plus TCZ or PANC- 1 cells incubated with PMA exceeded $350 \mathrm{pg} / \mathrm{ml}$.

rhTNF- $\alpha$ and TCZ reduced MMP-9 production by $\Delta=-10 \%$ in C28/I 2 chondrocytes.

Incubation of PANC-1 cells with rhIL-6 increased MMP-9 to a similar extent as was found for C28/I2 chondrocytes (Figure 2). However, whereas the combination of rhIL-6 plus sIL-6R reduced MMP-9 to an undetectable level in C28/I2 chondrocytes, the combination of rhIL-6 plus sIL-6R had no effect on MMP-9 produced by PANC-1.

In contrast, PANC-1 cells incubated with PMA $(30.7 \mathrm{ng} / \mathrm{ml})$, serving as the positive control for MMP-9 production [13], substantially increased MMP-9 production, compared to its DMSO-control group (Figure 2).

\section{Effect of TCZ concentration on MMP-9 production by C28/ I 2 chondrocytes}

We next examined the effect of varying the concentration of TCZ between $200 \mathrm{ng} / \mathrm{ml}$ and $800 \mathrm{ng} / \mathrm{ml}$ on MMP-9 production by C28/I2 chondrocytes in response to rhIL-6 $(50 \mathrm{ng} / \mathrm{ml})$. Although the average of duplicate determinations from the MMP-9 ELISA showed that TCZ $(200 \mathrm{ng} / \mathrm{ml})$ reduced rhIL-6-induced MMP-9 after $1 \mathrm{hr}$ by $\Delta=-$ $16 \%$ (Figure 3 ) this difference did not reach statistical significance. However, TCZ at concentrations ranging from $400 \mathrm{ng} / \mathrm{ml}$ to $800 \mathrm{ng} /$ $\mathrm{ml}$ significantly reduced MMP-9 after $1 \mathrm{hr}$ (Figure 3). Furthermore, the reduction in MMP-9 in response to the combination of rhIL-6 plus TCZ was sustained after $4 \mathrm{hrs}$ (Figure 3 ). Of note, concentrations of TCZ greater than $200 \mathrm{ng} / \mathrm{ml}$ did not increase its inhibitory effect on MMP-9 production at $1 \mathrm{hr}$ (Figure 3) or at $4 \mathrm{hrs}$ (Figure 3). The result of the chi-square analyses for all of the group comparisons is summarized in Table 1.

\section{ICC analysis of MMP-9 production by C28/I2 chondrocytes and PANC-1}

MMP-9 production was also analyzed by ICC using an antiMMP-9 antibody that is reactive with both pro-MMP-9 and activated MMP-9. The photomicrograph in Figure 4A shows the appearance of the negative C28/I2 chondrocyte control for MMP-9. This image was arrived at by processing the cells for ICC but without applying primary anti-MMP-9 antibody. The other photomicrographs (Figure 4B) show C28/I2 chondrocytes from the "no additions" control group which were identified by Metamorph" as MMP-9-positive (arrows) in 6 regions of the cover slip encompassing the microscopic fields enumerated for the ICC analysis.

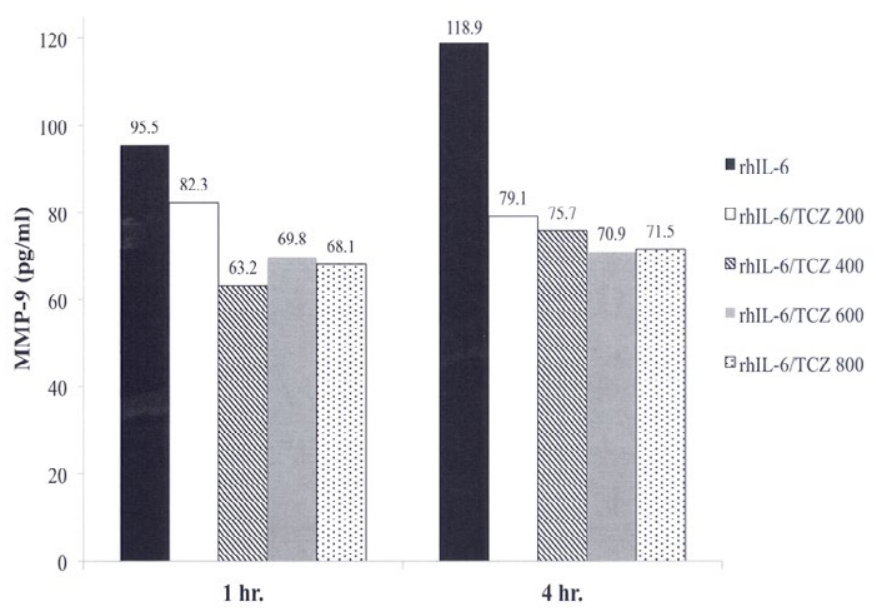

Figure 3. Effect of TCZ on rhIL-6-Mediated MMP-9 Production by C28/I2 Chondrocytes. The concentration of rhIL-6 was $50 \mathrm{ng} / \mathrm{ml}$. The concentration of TCZ was varied from 200 $\mathrm{ng} / \mathrm{ml}$ to $800 \mathrm{ng} / \mathrm{ml}$.

Table 1. $\chi^{2}$ Analysis: Effect of TCZ on MMP-9 Production by C28/I2 Chondrocytes.

\begin{tabular}{|c|c|c|c|}
\hline Group & {$[\mathbf{T C Z}]$} & $\mathbf{6 0}$ min & $\mathbf{4}$ hrs \\
\hline 1 & $200 \mathrm{ng} / \mathrm{ml}^{1}$ & $\chi^{2}=0.38 ; \mathrm{p}=0.54$ & $\chi^{2}=9.6 ; \mathrm{p}=0.002^{*}$ \\
\hline 2 & $400 \mathrm{ng} / \mathrm{ml}^{2}$ & $\chi^{2}=10.1 ; \mathrm{p}=0.001^{*}$ & $\chi^{2}=18.7 ; \mathrm{p}=1.5 \times 10^{-5 *}$ \\
\hline 3 & $600 \mathrm{ng} / \mathrm{ml}^{3}$ & $\chi^{2}=3.96 ; \mathrm{p}=0.046^{*}$ & $\chi^{2}=17.6 ; \mathrm{p}=2.6 \times 10^{-5 *}$ \\
\hline 4 & $800 \mathrm{ng} / \mathrm{ml}^{4}$ & $\chi^{2}=5.16 ; \mathrm{p}=0.02^{*}$ & $\chi^{2}=17.6 ; \mathrm{p}=2.6 \times 10^{-5 *}$ \\
\hline
\end{tabular}

Ratio of [TCZ] to [rhIL-6]: ${ }^{1} 4: 1 ;{ }^{2} 8: 1 ;{ }^{3} 12: 1 ;{ }^{4} 16: 1$

${ }^{*}$ p-value for significance was $<0.05$ 

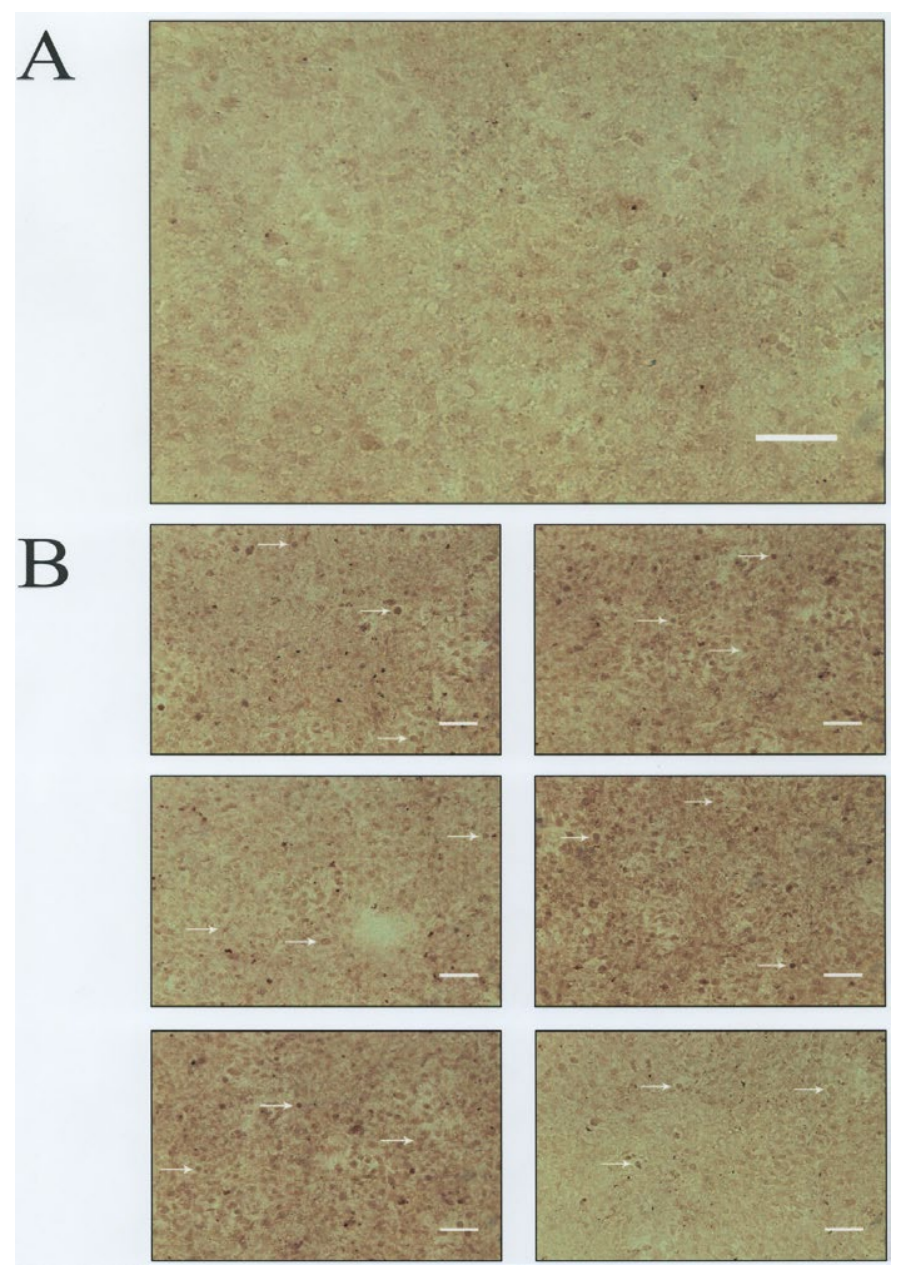

Figure 4. Anti-MMP-9 Antibody-Mediated Immunocytochemistry (ICC).

Panel A: C28/I2 chondrocytes-negative control $(-=100 \mu \mathrm{m})$.

Panel B: Arrows indicate MMP-9-positive chondrocytes $(-=100 \mu \mathrm{m})$

The ICC of anti-MMP-9 antibody-positive C28/I2 chondrocytes treated with rhIL-6 $(50 \mathrm{ng} / \mathrm{ml})$ for $24 \mathrm{hrs}$ is shown in Figure 5 and compared to C28/I2 chondrocytes in the "no additions" control or $10 \%$ FBS control group. The quantitative analysis showed that rhIL-6 significantly increased the number of anti-MMP-9 antibody positive chondrocytes compared to the "no additions" control group [i.e. DMEM/F12 (1:1) containing 0.5\% FBS; $\left.\left(\mathrm{p}=1.23 \times 10^{-7}\right)\right]$. As a further determination regarding the specificity of the rhIL-6 effect on C28/I2 chondrocyte MMP-9 production, PANC-1 cells were also incubated with rhIL-6 $(50 \mathrm{ng} / \mathrm{ml})$ for $24 \mathrm{hrs}$. The number of MMP-9-positive PANC-1 cells was not significantly altered by rhIL-6 ("no additions" control, Arbitrary Units, $17.3 \pm 0.28$; rhIL-6, $15.5 \pm 0.78$; mean \pm SD, $\mathrm{n}=5 ; \mathrm{p}=0.67)$.

C28/I2 chondrocytes maintained in DMEM/F12 (1:1) containing $10 \%$ FBS for $24 \mathrm{hrs}$ also increased the number of MMP-9-positive chondrocytes compared to the "no additions" control containing $0.5 \%$ FBS $\left(\mathrm{p}<2 \times 10^{-3}\right)$. This result provided substantive justification for maintaining C28/I2 chondrocytes in 0.5\% FBS for determining MMP9 production in the various treatment groups.

Although C28/I2 chondrocytes incubated with rhIL-6 alone had a significantly increased number of MMP-9-positive chondrocytes compared to the "no additions" control group, the combination of rhIL-6 plus sIL-6R also significantly increased the number of MMP9-positive chondrocytes compared to sIL-6R $\left(\mathrm{p}=3.1 \times 10^{-5}\right)$ (Figure $6)$, whereas sIL-6R alone significantly reduced the number of MMP9-positive chondrocytes compared to rhIL-6 $\left(\mathrm{p}=2.2 \times 10^{-4}\right)$. This was also the case for the rhIL-6 plus TCZ group when compared to rhIL-6 $\left(\mathrm{p}=9.7 \times 10^{-4}\right)($ Figure 6$)$. Importantly, TCZ alone had no significant effect ( $\mathrm{p}=0.07$ ) on chondrocyte MMP-9-positivity compared to rhIL-6.

\section{ICC analysis of NGAL production by $\mathrm{C} 28 / \mathrm{I} 2$ chondrocytes}

The number of NGAL-positive cells was significantly reduced $\left(\mathrm{F}=48.86 ; \mathrm{p}=4.3 \times 10^{-4}\right)$ by sIL-6R compared to the "no additions" control group as well as by the combination of rhIL-6 plus TCZ $\left(\mathrm{F}=19.00 ; \mathrm{p}=4.7 \times 10^{-3}\right)$ (Figure 7). By contrast, none of the other incubation conditions, altered NGAL production (Figure 7). Notably, rhIL-6 plus TCZ failed to significantly reduce NGAL compared to rhIL-6. In general, the ICC analysis of the various treatment groups for NGAL-positive chondrocytes mirrored results obtained with the NGAL ELISA (data not shown).

\section{Discussion}

The principal objectives of this study were 1) to determine the extent to which rhIL-6 stimulated MMP-9 and NGAL production by immortalized human juvenile chondrocyte lines; and 2) to determine

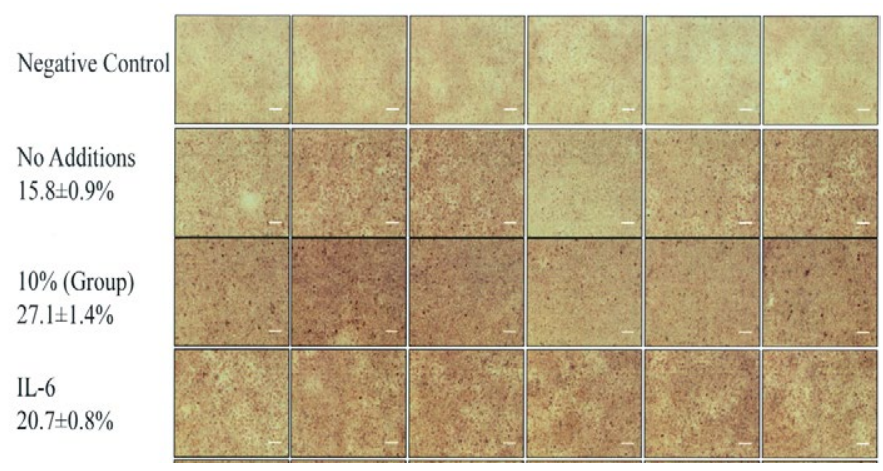

Figure 5. Effect of $0.5 \% \mathrm{FBS}, 10 \%$ FBS or rhIL-6 (50 ng/ml)-containing DMEM/F12 (1:1) on MMP-9 Production by C28/I2 Chondrocytes $(-=100 \mu \mathrm{m})$.

Values are mean $\pm \mathrm{SD}$ ( $\mathrm{n}=6$ microscopic fields)
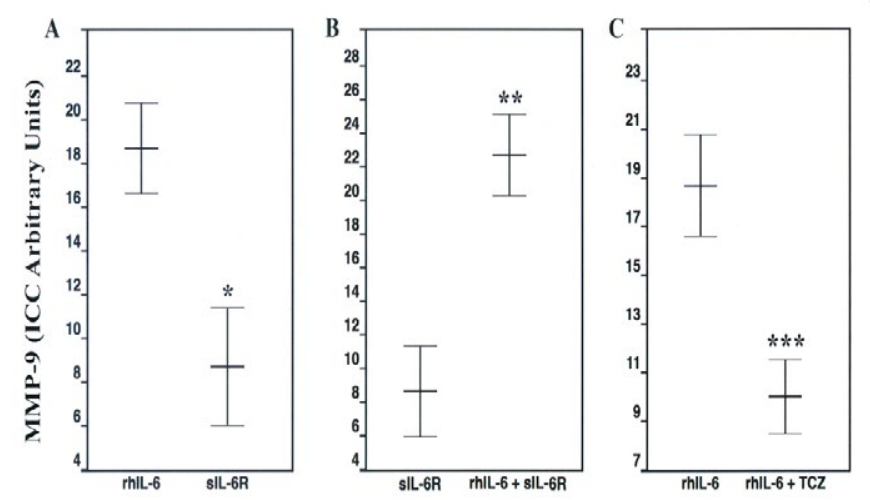

Figure 6. Effect of Various Incubation Conditions on MMP-9 Production by C28/I2 Chondrocytes: Anti-MMP-9 Antibody-Mediated ICC. Values are mean $\pm \mathrm{SD}(\mathrm{n}=5)$ $* \mathrm{p}=2.2 \times 10^{-4} ; * * \mathrm{p}=3.1 \times 10^{-5} ; * * * \mathrm{p}=9.7 \times 10^{-4}$ 

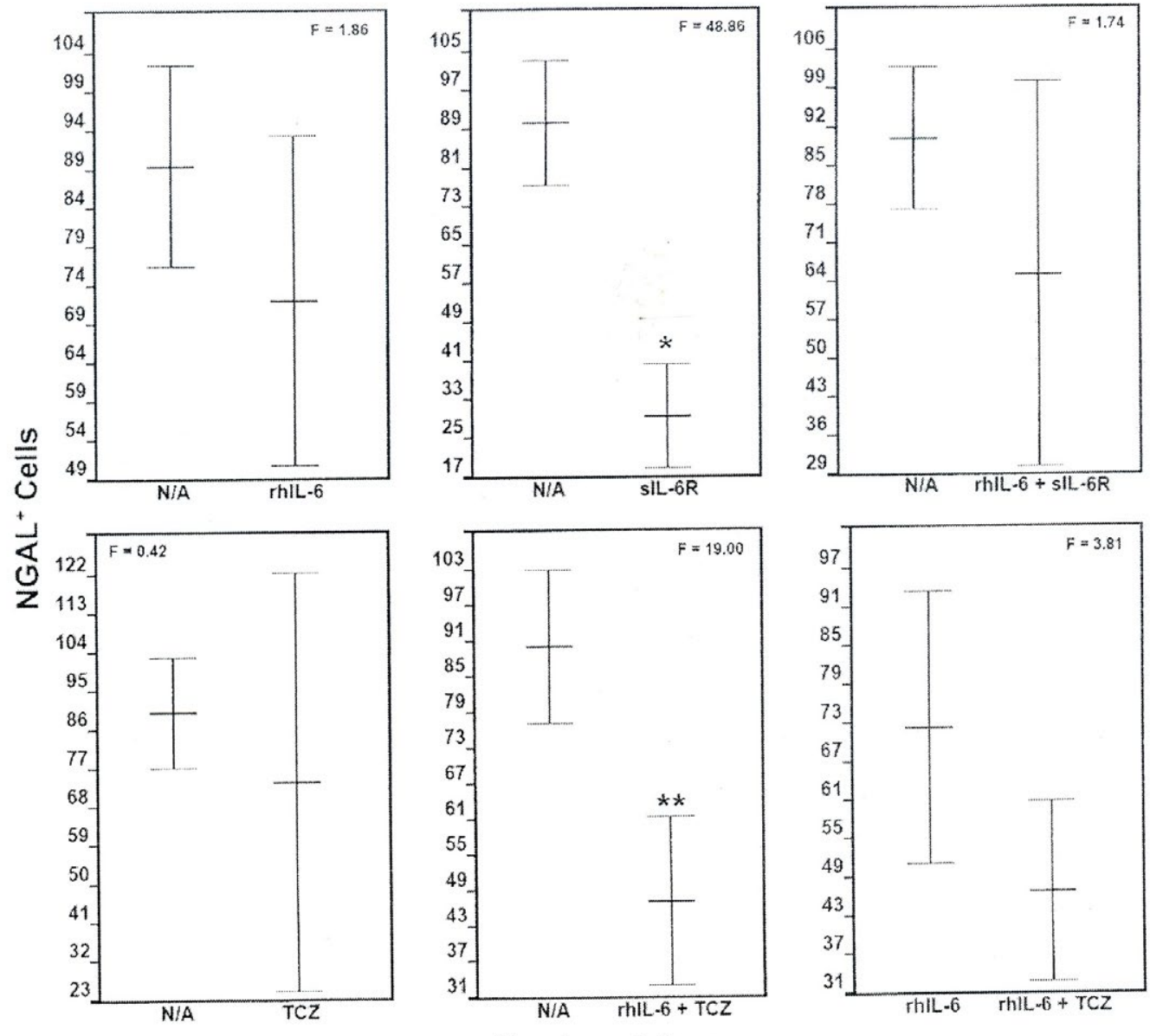

Treatment Group

Figure 7. The Effect of Various Incubation Conditions on NGAL Production by C28/I2

Chondrocytes: Anti-NGAL Antibody-Mediated ICC. Among the various incubation conditions, only sIL-6R $\left(\mathrm{p}=4.3 \times 10^{-4}\right)$ and the combination of rhIL-6 + TCZ $\left(\mathrm{p}=4.7 \times 10^{-3}\right)$ significantly reduced the number of NGAL-positive cells compared to the "no additions" N/A control group. However, the combination of rhIL-6 plus TCZ did not decrease the number of NGAL-positive cells compared to rhIL-6 alone. Values are mean \pm SD $(n=5)$.

whether sIL-6R or TCZ, the latter a fully humanized $\operatorname{IgG1}(\kappa)$ monoclonal antibody which neutralizes the interaction between IL-6 and IL-6R $\alpha$, augmented or inhibited MMP-9 and/or NGAL.

The principal result of MMP-9 ELISA was that rhIL-6 alone stimulated MMP-9 production by C28/I2, but not T/C28a2 immortalized human chondrocytes. In the MMP-9 ELISA, the combination of rhIL-6 and sIL-6R significantly decreased MMP9 production in C28/I2 chondrocytes and most importantly, the combination of rhIL-6 plus TCZ also reduced MMP-9 compared to rhIL-6. In analyzing both the MMP-9 ELISA and anti-MMP-9 ICC results, we found that the combination of rhIL-6 plus TCZ reduced MMP-9, but TCZ by itself had no effect on chondrocyte-derived MMP9 compared to rhIL-6. These data strongly suggested that neutralizing the interaction between rhIL- 6 and IL-6R with TCZ in vitro reduced C28/I2 chondrocyte MMP-9 production. However, it remains to be determined the extent to which TCZ would be an effective therapeutic strategy to inhibit MMP-9 production by articular chondrocytes in vivo. This should first be tested in well-validated animal models of RA and osteoarthritis. Although TCZ, a potent inhibitor of IL-6-mediated JAK/STAT activation [5] reduced MMP-9 production, TCZ will not be helpful in sorting out which of three potential IL-6 pathways (i.e.
IL-6Ra/gp130, mIL-6R, sIL-6R) is altered by TCZ, since TCZ does not selectively inhibit the IL-6R $\alpha / g p 130$ pathway [14].

Even though we employed an MMP-9 ELISA and an anti-MMP-9 antibody-based ICC quantitative analysis, we could not determine the extent to which any of the various treatment groups altered either or both pro-MMP-9 and/or activated MMP-9 because the anti-MMP-9 antibody used in the ICC analysis does not distinguish between the two enzyme forms. Thus, we have come to recognize this as an important limitation of this study.

It is well known that IL-6 activates the JAK/STAT pathway in many cell types [5], including chondrocytes $[4,11]$. In that regard, only two previously published in vitro studies were designed to correlate MMP-9 production per se with STAT protein phosphorylation. In one of these studies, Dechow et al. [15] indicated that there appeared to be a "strong" relationship between MMP-9 gene expression and the level of tyrosine phosphorylated STAT3 (termed STAT3c) in primary breast cancer specimens. In the other study, Kothari et al. [16] showed that IL-6-induced macrophage MMP-9 gene expression was mainly dependent on p-ERK1/2 although MMP-9 gene expression was also inhibited by a JAK-dependent product, identified as IL-10. In view 
Meszaros EC (2015) Blockade of recombinant human IL-6 by tocilizumab suppresses matrix metalloproteinase-9 production in the C28/I2 immortalized human chondrocyte cell line

of these results, future in vitro experiments should determine the precise relationship between activation of STAT proteins by rhIL-6 and activation of pro- $M M P-9$ gene activity as well as identifying any cofactors that may also be involved in pro- $M M P-9$ gene expression [17]. In that regard, it is generally agreed that these studies will have to employ quantitative PCR for assessing MMP-9 gene expression as well as gelatin-impregnated zymography to determine the extent to which pro-MMP-9 is activated under the various culture conditions. In fact, "gelatin-zymography" will be critical to this assessment in the analysis of pro-MMP-9 activation [18]. This is due to the fact that intracellular processing of latent pro-MMP-9 can produce different forms of active gelatinase, with molecular sizes ranging from $64 \mathrm{kDa}$ to $82 \mathrm{kDa}$.

Finally, rhIL-6 failed to stimulate NGAL production in C28/I2 chondrocytes. This result contrasted with previous results obtained for NGAL production by human osteoarthritis chondrocytes in response to rhIL-1 $\beta$ [9]. This difference may merely represent a differential response of human chondrocytes to IL- $1 \beta$ versus IL- 6 or differences between human OA chondrocytes and the C28/I2 human chondrocyte line.

It noteworthy that Zerenga et al. [19] did not find any evidence for NGAL protein in either normal human adult articular cartilage or tracheal cartilage or for that matter, any NGAL produced by cultured rat embryo chondrocytes. However, NGAL protein synthesis could be induced in the rat chondrocyte cultures by lipopolysaccharide (LPS) [19], indicating that the NGAL gene was up-regulated by LPS and potentially by other pro-inflammatory mediators.

Changes in NGAL production were also evaluated following treatment of C28/I2 chondrocytes with rhIL-6 plus sIL- 6 or rhIL-6 plus TCZ. Thus, whereas the combination of rhIL- 6 and TCZ inhibited MMP-9 production compared to rhIL- 6 alone, the results of the antiNGAL antibody ICC showed that rhIL-6 plus TCZ did not significantly affect NGAL production compared to rhIL-6, although rhIL-6 plus TCZ significantly reduced NGAL compared to the "no additions" control group.

Finally, the results of this in vitro study could have substantive implications for potentially employing TCZ to regulate rhIL-6-induced MMP-9 and/or NGAL production by articular cartilage in various arthritic conditions. Since MMP-9 forms a complex with NGAL with the MMP-9/NGAL complex maintaining MMP-9 in its activated state [10], the putative inability of TCZ to effectively regulate C28/ I2 chondrocyte NGAL production may have significance for future translational research. Although sIL-6R as well as the combination of rhIL-6 plus TCZ significantly dampened NGAL production compared to the "no additions" control group, the overall results suggested that employing therapeutic levels of TCZ in arthritic disorders might be most effective for regulating elevated levels of chondrocyte NGAL when NGAL is over-produced in response to the combined effects of other pro-inflammatory cytokines implicated in arthritis which include, IL-1 $\beta$ [4], TNF- $\alpha$ [4], IL-17A [20] and OSM [21].

\section{Acknowledgements}

This study was supported by a contract between Genentech/ Roche Group, Charles J. Malemud, Ph.D., Principal Investigator, and Case Western Reserve University (CWRU), and by NICHD R01069819-01A1, Principal Investigator; Sam Mesiano, PhD and NEI P30-EY11373, The CWRU Visual Sciences Core Center Grant; CoPrincipal Investigators, Eric Pearlman and Irina Pikuleva,. We thank Scott Howell, Ph.D. for his support in performing the ICC analyses.

\section{Conflicts of interest statement}

The authors declare no conflicts of interest.

\section{References}

1. Malemud CJ (2006) Matrix metalloproteinases (MMPs) in health and disease: an overview. Front Biosci 11: 1696-1701. [Crossref]

2. Burrage PS, Mix KS, Brinckerhoff CE (2006) Matrix metalloproteinases: role in arthritis. Front Biosci 11: 529-543. [Crossref]

3. Martel-Pelletier J, Welsch DJ, Pelletier JP (2001) Metalloproteases and inhibitors in arthritic diseases. Best Pract Res Clin Rheumatol 15: 805-829. [Crossref]

4. Malemud CJ (2013) Immunotherapies and rheumatoid arthritis-Introduction. J Clin Cell Immunol (S6:001).

5. Shetty A, Hanson R, Korsten P, Shawagfeh M, Arami S, et al. (2014) Tocilizumab in the treatment of rheumatoid arthritis and beyond. Drug Des Devel Ther 8: 349-364. [Crossref]

6. Kokenyesi R, Tan L, Robbins JR, Goldring MB (2000) Proteoglycan production by immortalized human chondrocyte cell lines cultured under conditions that promote expression of the differentiated phenotype. Arch Biochem Biophys 383: 79-90. [Crossref]

7. Goldring MB (2004) Culture of immortalized chondrocytes and their use as models of chondrocyte function. Methods Mol Med 100: 37-52. [Crossref]

8. Finger F, Schörle C, Zien A, Gebhard P, Goldring MB, et al. (2003) Molecular phenotyping of human chondrocyte cell lines T/C-28a2, T/C-28a4, and C-28/I2 Arthritis Rheum 48: 3395-3403. [Crossref]

9. Gupta K, Shukla M, Malemud CJ, Cowland J, Haqqi TM (2006) Neutrophil gelatinaseassociated lipocalin (NGAL) is produced by IL-1ß-stimulated human osteoarthritis chondrocytes and protects MMP-9 from degradation. Osteoarthritis Cartilage 14 Suppl B: S87-S88.

10. Gupta K, Shukla M, Cowland JB, Malemud CJ, Haqqi TM (2007) Neutrophil gelatinase-associated lipocalin is expressed in osteoarthritis and forms a complex with matrix metalloproteinase 9. Arthritis Rheum 56: 3326-3335. [Crossref]

11. Aida Y, Honda K, Tanigawa S, Nakayama G, Matsumura H, et al. (2012) IL-6 and soluble IL-6 receptor stimulate the production of MMPs and their inhibitors via JAKSTAT and ERK-MAPK signalling in human chondrocytes. Cell Biol Int 36: 367-376. [Crossref]

12. Kotake S, Sato K, Kim KJ, Takahashi N, Udagawa N, et al. (1996) Interleukin-6 and soluble interleukin- 6 receptors in the synovial fluids from rheumatoid arthritis patients are responsible for osteoclast-like cell formation. J Bone Miner Res 11: 88-95. [Crossref]

13. Haq M, Shaeii AE, Zervos EE, Rosemurgy AS (2000) In vitro and in vivo matrix metalloproteinase production by pancreatic cancer cells and by distant organs. Int $J$ Surg Investig 1: 459-465. [Crossref]

14. Rose-John S, Waetzig GH, Scheller J, Grötzinger J, Seegert D (2007) The IL-6/sIL-6R complex as a novel target for therapeutic approaches. Expert Opin Ther Targets 11: 613-624. [Crossref]

15. Dechow TN, Pedranzini L, Leitch A, Leslie K, Gerald WL, et al. (2004) Requirement of matrix metalloproteinase-9 for the transformation of human mammary epithelial cells by Stat3-C. Proc Natl Acad Sci U S A 101: 10602-10607. [Crossref]

16. Kothari P, Pestana R, Mesraoua R, Elchaki R, Khan KM, et al. (2014) IL-6-mediated induction of matrix metalloproteinase- 9 is modulated by JAK-dependent IL-10 expression in macrophages. J Immunol 192: 349-357. [Crossref]

17. Malemud CJ, Pearlman E (2009) Targeting JAK/STAT signaling pathway in inflammatory diseases. Curr Signal Transduct Ther 4: 201-221.

18. Toth M1, Sohail A, Fridman R (2012) Assessment of gelatinases (MMP-2 and MMP-9) by gelatin zymography. Methods Mol Biol 878: 121-135. [Crossref]

19. Zerenga B, Cermelli S, Michelis B, Cancedda R, Cancedda FD, et al. (2000) Expression of NRL/NGAL (neu-related lipocalin/neutrophil gelatinase-associated lipocalin) during mammalian embryonic development and in inflammation. Eur J Cell Biol 79(3): 165172. [Crossref] 
Meszaros EC (2015) Blockade of recombinant human IL-6 by tocilizumab suppresses matrix metalloproteinase-9 production in the C28/I2 immortalized human chondrocyte cell line

20. Moran EM, Mullan R, McCormick J, Connolly M, Sullivan O, et al. [2009] Human rheumatoid arthritis tissue production of IL-17A drives matrix and cartilage degradation: synergy with tumour necrosis factor-alpha, oncostatin $\mathrm{M}$ and response to biologic therapies. Arthritis Res Ther 11(4): R113. [Crossref]
21. LiWQ, Dehnade F, Zafarullah M(2001) Oncostatin M-induced matrix metalloproteinase and tissue inhibitor of metalloproteinase-3 genes expression in chondrocytes requires Janus kinase/STAT signaling pathway. J Immunol 166(5): 3491-3498. [Crossref]

Copyright: $\mathbb{C} 2015$ Meszaros EC. This is an open-access article distributed under the terms of the Creative Commons Attribution License, which permits unrestricted use, distribution, and reproduction in any medium, provided the original author and source are credited. 